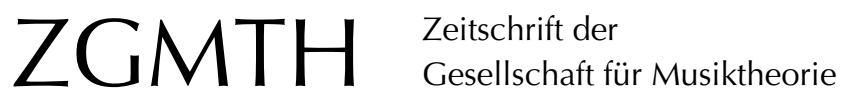

McKay, Nicholas (2007): On Topics Today. ZGMTH 4/1-2, 159-183.

https://doi.org/10.31751/251

(C) 2007 Nicholas McKay

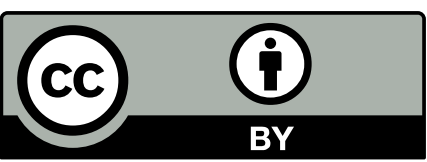

Dieser Text erscheint im Open Access und ist lizenziert unter einer Creative Commons Namensnennung 4.0 International Lizenz.

This is an open access article licensed under a

Creative Commons Attribution 4.0 International License.

veröffentlicht / first published: 01/01/2007

zuletzt geändert / last updated: 22/03/2009 


\title{
On Topics Today
}

\author{
Nicholas McKay
}

This article surveys the state of so-called topic theory today. It charts its development through two 'generations' of 'topic theorists'. The first is constructed around three influential texts: Leonard Ratner's seminal book that established the discipline in its own right, Classic music: expression, form and style (1980); Wye Allanbrook's Rhythmic gesture in Mozart: Le nozze di Figaro and Don Giovanni (1983); and Kofi Agawu's Playing with signs: a semiotic interpretation of classical music (1991). The second comprises significant advances in topic theory essayed through two further pairs of texts: Robert Hatten's Musical meaning in Beethoven: markedness, correlation, and interpretation (1994) and Interpreting musical gestures, topics, and tropes: Mozart, Beethoven, Schubert (2004); and Raymond Monelle's Linguistics and semiotics in music (1992) and The sense of music: semiotic essays (2000).

Susan McClary's caricature of musicology (read "old" musicology; a. k. a. formalist analysis) as an autistic discipline suffering from Asperger syndrome' is not so far removed from the truth. Formal analysis is, by its very nature, disinclined towards - if not incapable of-reading expressive intentions encoded in music's gestures or voices. Like those afflicted with Asperger syndrome, its practitioners are "generally 'blind to social meanings' and create instead their own networks of correlations 'that bring to mind the elaborate pseudoscientific systems of numerology and astrology'."' ${ }^{2}$ Whereas this is considered a pathological disorder in neurological science, such insensitivity to socio-semantics became in twentieth-century musicology not only the norm, but something of an ideological virtue. Under the legacies of Hanslick (1986), Schenker (1979) and Stravinsky (1924; 1990; 1994), "modern" musicologists developed a post-Wagnerian, structuralist conceit to "scoff at those who would impose affective significance on to [abstract, geometric] musical patterns." ${ }^{3}$

Of course, this was not always the case. Nor is all music equal in this respect. Certain repertoires invite or demand greater sensitivity to expressive meanings. Works of music theater and those setting music to text are obvious cases. They come with an automatic and, one might imagine, inextricable semantic component. Yet even these works can display a further layer of narrative comment encoded in the music; much as Noske finds in Mozart's deployment of the "aristocratic" minuet as a "social weapon" in The Marriage

1 McClary 2001, 326.

2 McClary 2001, 326 citing Oliver Sacks.

3 McClary 2001, 326. 
of Figaro. ${ }^{4}$ Conversely, they can be made to abandon their referential associations altogether. "Expression has never been an inherent property of music," said Stravinsky, ${ }^{5}$ wo set about converting his Rite of Spring from a theater ballet into "pure" concert hall music in an act of aesthetic abstraction that was a mere overture to his neoclassic project. ${ }^{6}$

So too different stylistic epochs inevitably invite and reward differing musicological sensitivities. Newcombe, for example, reminds us that "Any analysis of Romantic music which ignores the semantic and narrative aspects is simply unhistorical." ${ }^{7}$ Likewise, musicological climates change over time. The harsh winter of the twentieth-century's formalist discontent with "outmoded" expressive attitudes to music thawed to usher in the spring of a "new" contextual musicology. It blossomed in a poststructuralist climate-one in which McClary's caricature of autistic musicology thrives-and is now more prone to scoff at those who do not "read" affective significance in musical patterns, whether that expressive meaning is hermeneutically constructed or historically reconstructed. ${ }^{8}$

Today's "postmodern" musicology thus once again values music's elusive "semantic" qualities. Running in the wake of Barthes and Derrida's impact on literary theory, it attempts to construct multiple subjective visions of what a musical work might mean through diverse acts of creative reader-oriented interpretation; situating expressive meaning firmly in the eye of the beholder and not in the work itself. ${ }^{9}$ Alternatively-but with a related eye on "new historicism"10_it attempts to reconstruct music's expressive meanings in context, valuing a humanist engagement with music for "what it is" (inclusive of its so-called "extramusical" ideas), over and above the constructivist mechanics of "how it's done."11

The subjective and plural interpretations arising from these postmodern "readings," however, are notably different to the shared "expressive" meanings offered by musical topoi: familiar, expressive, rhetorical gestures encoded in referential musical patterns. These conventional musical signs, or "commonplaces" of style, are distilled from—or

4 Noske asserts that the three 'aristocratic' minuets ("Se vuol ballare, signor contino;" "Signore cos' $^{\prime}$ è quell stupore?" and "Tutto è tranquillo e placido") sung by the lower ranking servants, Figaro and Susanna, assume "the function of a social weapon" as expressions of mockery or bitterness that ape the musical manners of the aristocracy (1990, 32-5).

5 Stravinsky 1990, 53.

6 In a bold aesthetic conversion of The Rite of Spring from what Stravinsky termed an "anecdotique" work (i.e. an ethnic, primitivist ballet conveying an explicit narrative story, originally conceived as a musical image of a sacrificial dance) to an "architectonic" work (i.e. one of absolute music conceived as a purely musical construct), Stravinsky, with formalist intent, uprooted his narrative ballet from the theater, divorced it from its "affective" significations and transplanted it to the "pure music" world of the concert hall and gramophone recording (see Taruskin 1995). In a similar vein Stravinsky exploited his "rejoicing discovery" (i.e. his realisation that words could be atomized into mere syllables of sound with complete abandon for their linguistic and semantic protocols) to deter the listener from importing the meaning of his texts to his "pure" music (see Taruskin 1987).

7 Newcombe 1984; cited Monelle 1992, 220.

8 Cook (1996, 109) draws this distinction in his review of Hatten (1994) and Tarasti (1994).

9 e.g. Kerman 1980, 1985; Kramer 1990, 1995; McClary 2002; Subotnik 1988.

10 e.g. Taruskin 1996, 1997.

11 Taruskin 2003, 276. 
grafted onto (depending on one's critical stance) — the rhetorical surface of music in the analytical/interpretative process known as "topic-theory." ${ }^{12}$ Its aim is to explicate the expressive qualities of ostensibly abstract (and typically) classical music. The motivation of the scholars who practice it stems primarily from a desire to help ("autistic") musicology "to recover from the repression of expressive discourse by a formalist aesthetics."13 Both in this respect, and with regard to the degree of creative interpretation necessary to make sense of music's referential signs, it occupies common ground with both the new historicism and reader-oriented approaches of current musicology. Yet at the same time, it continues to be somewhat marginalized as a curio of music semiotics; a sub-discipline that has yet to gain full entry into the hegemonic club of musicology.

In the Anglo-American tradition, five scholars in particular have proved central to the emergence and development of so-called "topic theory"14 as a recognizable force in contemporary musicology built on the influence both of earlier theorists like Koch, Kolmann, Riepel, and Sulzer ${ }^{15}$ and more recent twentieth-century theorists such as Tovey and Rosen (see Figure 1). ${ }^{16}$ The "first generation" trio of Leonard Ratner (1980)—topic theory's founding father-and his two disciples, Kofi Agawu (1991) and Wye Allanbrook (1983), established this mode of "analysis" or "interpretation" (a contentious distinction) as a new branch of music semiotics. The "second generation," headed by the work of Robert Hatten $(1994 ; 2004)$ and Raymond Monelle (2000), has subsequently sought to address some of its semantic, expressive, semiotic, and socio-historical shortcomings. Their later work highlights the need for-and offers compelling demonstrations ofmore refined acts of interpretation. It probes deeper into the cultural and historical underpinnings of the complex sign functions of expressive gestures, considers the utility of these gestures for analysis/interpretation and performance, and considerably broadens the scope of the Agawu-Ratner "universe of topics" to encompass a wider range of expressive gestures. Together they offer an intriguing glimpse into the future of what today we still conservatively call "topic theory."

12 Topic theory has come to be associated primarily as an analytical tool honed on eighteenth-century classicism. This is perhaps not surprising given the highly convention-bound nature of the era's artistic practice and social conduct. But the eighteenth century only marks the epitome of common practice repertoire that propagated the growth of topics as rhetorical commonplaces because their precedents are found in earlier music: the sixteenth- and seventeenth-century madrigal and tragedie lyrique, for example.

13 Hatten 1994, 228.

14 The not unproblematic ascription of the term "theory" (with its unhelpful connotations of objective positivism) to what is essentially a semiotic process of interpretation, is perhaps symptomatic both of the 1980s American climate in which the 'subfield' emerged and of Agawu's influential allying of referential topics with structural Schenkerism through his concepts of extroversive [i.e. referential topoi] and introversive [i.e. the "pure signs" generated by a work's musical structure] semiosis.

15 Hill 1981, 64.

16 These antecedent musicologists are representative of just some of the influences underpinning the emergence of present day topic theory. More recent continental theorists have also contributed to the growth of the practice but these lie largely outside of the Anglo-American tradition on which this article is focussed. 


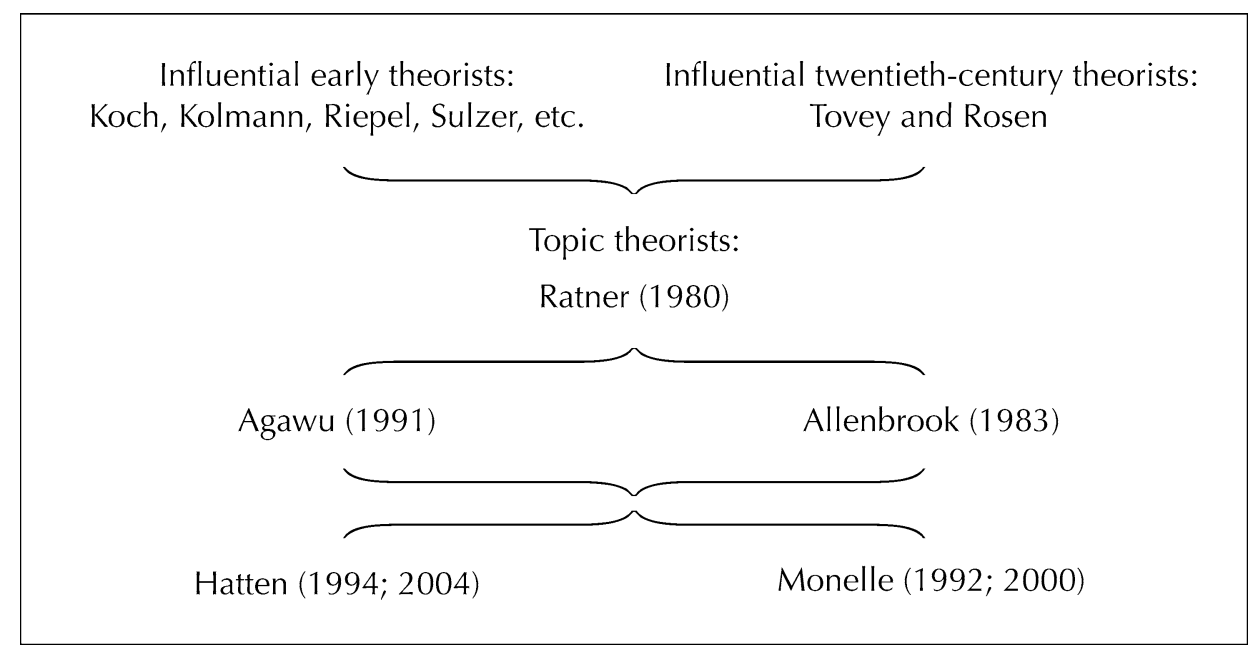

Figure 1: The (concise) universe of topic theorists on which the Anglo-American tradition is built

"Topic theorists," then, are the intended exception to McClary's caricature of autistic, formalist musicology. But it is a common misconception that topic theory seeks to eradicate analytical formalism altogether. These scholars navigate a precarious path through semantic "interpretation" and structural "analysis." Cook is right to observe that "what is at stake" in their endeavors "is nothing less than the rehabilitation of music as meaning, which a generation of formalism did its best to repress, but failed."17 But Whittall is also on the nail of topic theory when he observes that Hatten's (1994) objective "is not a complementary 'repression' of formalism" but "a dialogue between it and 'expressive discourse ." $^{\prime \prime 18}$

This dialogue is the established arena of topic theory, something that Hatten and his fellow topic theorists "construe as involving both structuralist and hermeneutic approaches to the relationship of sound and meaning. ${ }^{\prime 19}$ Despite a common misapprehension, topic theory is not simply the art of appending style labels to musical moments. Its hermeneutic elegance lies in its ability to explore the interplay of style and structure. Topic theory flirts with formalism while simultaneously repudiating it. It addresses "the 'problem' of meaning in music," not through the insensitivity of the quasi-scientific "formalist correspondences" ${ }^{\prime 20}$ that plague Nattiez's $(1975 ; 1982)$ rigorous "neutral level" application of Ruwet's (1987) distributional charts, ${ }^{21}$ but through a heightened cultural sen-

17 Cook 1996, 123.

18 Whittall 1996, 116.

19 Hatten 1994, 2.

20 McClary 2001, 326.

21 McClary caricatures Nattiez's distributional analysis as the paradigm of "autistic" musicologists who "often restrict the scope of their inquiries to formalist correspondences-as though they were trying to decipher texts in an unknown tongue without the benefit of a Rosetta stone" $(2001,326)$. 
sitivity to the inbuilt "intertextuality of the classical style."22 Topic theory, in other words, belongs to what Cumming (2000) calls the "semantic" or "referential" brand of semiotics in contradistinction to Nattiez's more infamous "structuralist" brand. But the semantic insights afforded by topic theory are rarely the result of "extramusical" reference alone. They emerge through the interaction of topics and syntax; through processes Agawu demarcates, with Jakobson' $\mathrm{s}^{23}$ industry standard terms, as extroversive (the "referential signs" of topoi) and introversive (the "pure signs" of music syntax) semiosis. ${ }^{24}$

One reason why the introversive formalism of topic theory is often overlooked, relative to its referential extroversive dimension, may be to do with the respective inclusion and exclusion of Nattiez and Agawu from the last of the core analysis textbook primers. ${ }^{25}$ The sudden collapse of the "how to do analysis" book market-a victim of the 1990s "new" musicological devaluation of analysis as an outmoded "formalist" practiceentombed Nattiez's $(1975 ;$ 1982) taxonomic-empirical, "neutral level" method in the analysts" collective psyche. It became the third of the holy trinity of "old testament" analysis "methods" along with Schenker's (1979) voice-leading and Forte's (1973) pitch class theory. ${ }^{26}$ The collapse enabled an emerging topic theory to define itself in the 1990s as the work not of "analysis" (something one might find in core analysis text books), but of "hermeneutics." ${ }^{27}$ This future-proofing of Ratner's "'soft' semiotic" ${ }^{\prime 28}$ topic theory in the "new testament" of interpretation was to a considerable extent symptomatic of the trumping of structuralism (including Nattiez's "'hard' semiotics") with the zeitgeist call for more culture-sensitive "readings" of music. Topic theory, despite the theoretical implications of its name, has thus managed to side-step Kerman's (1980) call for us "to get out of analysis" by recourse to its "softer" hermeneutics of extroversive semiosis. Introversion, let us not forget, is a classic symptom of autism. The "referential link with the exterior

22 Allanbrook 1996, 134.

23 Jakobson 1971, 125.

24 Agawu 1991, 23.

25 i.e. Dunsby and Whittall 1988; Cook 1992.

26 Even though Nattiez (1990) would go on to retract much of the linguistic rigour and formalist strictures of his distributional charts and neutral level ideals in his later writing; a point Cook also observes while noting that Nattiez nonetheless remained committed to the analysis of music's syntactic structure while topic theory sought to interpret its semantic expression $(1996,106)$.

27 Agawu (1999, 145) draws a distinction in music semiotics between "hermeneutics" (topic theory readings of music) and "analysis" (i.e. neutral level, distributional music semiotics). It is a manifestation of music's "ultimately false," "extrinsic-intrinsic dichotomy" (i.e. music's polarity between referring outside of itself [the domain of hermeneutics] vs. its self-referential tendency [the domain of analysis]). Agawu further lists "rough equivalents" of this extrinsic-intrinsic opposition: "semantic-syntactic," "subjective-objective," "extra-musical-musical," "extroversive semiosis-introversive semiosis" (Jakobson 1985), "extra-generic-congeneric" (Coker 1972, 60-88 and 144-70), and "exosemantic-endosemantic" (Dahlhaus 1991, 11).

28 Agawu (1999, 154) distinguishes between the "hard" semiotics of pitch-based structuralism [i.e. Nattiez] and the "broader perspectives" of "soft semiotics" that stem from "a more anthropological view of the musical work;" a view he divides into three categories: "music and the emotions, topoi, and song." 
world"29 that topic theory supplies thus ensures its survival in a post-analysis climate. Viewed more radically, this may ultimately ensure the survival of "analysis" itself.

Topic theory's distanced relationship with structuralism then is something of a divorce of convenience: it is far more reliant on formalism than is apparent from its rhetoric of expressive musical meaning. By maintaining a public distance from its introversive aspects, however, it is tolerated in, if not wholly accepted by, the fashionable circles of contemporary musicology. In many respects this has occurred in spite of the critical responses to Agawu's Playing with Signs (1991) — the text that first sought to build an analytical method out of Ratner's taxonomy of topics, and in the process brought it to a much wider audience. Drabkin's largely positive verdict on this landmark text is duly muted by his rating of Agawu's project as little more than simplified Schenker plus style: "welcome news for scholars who see themselves neither as pure theorists occupied with the nature of musical composition nor as simply historical musicologists who excavate its sources, but as something of a hybrid of the two, for whom every aspect of musical knowledge is potentially of concern." ${ }^{30}$ Hatten $^{31}$ critiques on similar grounds: Agawu draws short of interpreting the expressive significance of topics, focusing instead on meaning derived from the "play" of referential topics (extroversive semiosis) with the "pure signs" (introversive semiosis) of musical syntax. And though this critique prepares the ground for Hatten's own (1994) project-which demonstrates a far greater degree of expressive interpretation-Cook in turn faults Hatten for being "a closet absolutist:" ${ }^{2}$ he "seeks to add an expressive dimension to analytical practice," but "in practice, if not in theory, expression emerges for the most part as a supplement to structure." ${ }^{\prime 33}$ Striking the right balance between style and syntax, then, has become the benchmark for any topic theory. Agawu succinctly formulates the problem: topics "point to the expressive domain, but they have no syntax." ${ }^{34}$ This prompts Caplin to pose the fundamental question behind every topic theory: "what motivates or constrains the succession of various topics within a work. Are there, in fact, rules or motivating forces that guide the ordering of topics?." 35

The value of Ratner's seminal text, Classic Music: Expression, Form, and Style (1980), lies less in any analytical balance it seeks to strike between style and syntax and more as an outright index or vast thesaurus of the materials of a musical language that, he asserts, was understood by eighteenth-century composers, performers, and listeners alike. Referential topics are thus presented rather passively as objects of historical authenticity that offer insights for the analyst and performer into the poietic intentions of the com-

29 Jakobson 1971; cited Agawu 1991, 23.

30 Drabkin 1991, 387.

31 Hatten 1992, 88.

32 By which Cook means, "someone who believes that musical meaning is based exclusively on the relationships between constituent elements of the work itself,"' i. e. that "musical meaning is inherently musical'" (1996, 110; citing Nattiez 1990, 108; and Hatten 1994, 276).

33 Cook 1996, 112-3.

34 Agawu 1991, 20.

35 Caplin 2005, 113. 
poser. "For analysis, the recognition of these expressive qualities, explicit or implicit, is illuminating, often providing a clue to a striking aspect of structure; for performance, such recognition is essential, since it points to the poetic implications of the music." ${ }^{\prime 36}$ But the formulation of such a musical lexicon, however illuminating, merely compounds the problem: such "topical references are not arranged into coherent syntagms, as are the words of a language." ${ }^{\prime \prime}$ Instead of addressing this semantic shortcoming of topics, however, Ratner is largely content with pursuing their historical authenticity and utility.

In a concise article on the role of topical content when "Performing Mozart's Music," he lists a trichotomy of trichotomies (highlighted below in italics). These offer useful frames of reference for topics in terms of their historical grounding, utility, and signification. First, topical references are particularly prevalent on fortepiano repertoire because the instrument is a private, domestic surrogate designed to replicate the ensemble sounds of the theater, church, and chamber. ${ }^{39}$ Second, topics have different relevancies: for composers they comprise the "stock in trade material to be identified and selected" in a given composition, the "subjects to be incorporated in a discourse." For listeners or scholars they present "a kind of informal iconography-figures that have direct or symbolic meaning," and for performers, for whom "recognition and projection of topical content is of the greatest importance," they offer materials "to be sharply profiled and subtly nuanced." Third, topical references can signify "every level of dignity, from the highest to the lowest styles, every locale, from the church to the countryside, and every degree of specificity, from the descriptive pictorialisms (such as Turkish music, battle music and pastoral musettes) to characteristic dances, general affective stances, and even small figures that had gestural profile." ${ }^{\prime 40}$ Combined, Ratner argues that "these spectra of associations" thus "represented the eighteenth-century trend toward codification, toward the ordering of materials and processes, putting them into clear and accessible arrangements for ready use and immediate understanding." ${ }^{\prime 41}$

Agawu offers a far more systematic approach to the integration of style and syntax, constructing topical narratives charted either through referential "plots"42 or the "play" of syntax and style found in "structural rhythms."143 He achieves this by a fusion of Schenker and Ratner that is compelling in its simplicity. The second chapter's exposition of extro-

36 Ratner 1980, 30.

37 Monelle 1992, 227.

38 The subtitle of the edition of Early Music Vol. 19, No. 4 in which the article appeared.

39 Ratner explains that the fortepiano compensated "with lively action" for "what it lacked in full body or sound," thus explaining the rapid-fire juxtaposition of topics on the musical surface. "When the fortepiano takes up stances that are modelled on theatrical attitudes, it tends to touch upon them briefly and succinctly, creating (particularly in the music of Mozart) a kaleidoscopic continuity. The effect is analogous to cartoon sketching as contrasted with full-colour filled-in art" (Ratner 1991, 616).

40 Ratner 1991, 615-6, my italics.

$411991,615$.

42 Agawu 1991, 33-4.

43 Agawu 1991, 38-9. 
versive semiosis lays out his "universe of topics." ${ }^{\prime 44}$ Each topic offers a form of "associative signification." Collectively, they are grouped under two broad categories: musical types (various dances such as minuet, passepied, sarabande, siciliano, march etc.) and styles of music ("a heterogeneous collection of references" to military and hunt music, fanfares, horn calls, singing style, brilliant style, French overture, Turkish music, Sturm und Drang, sensibility, learned style etc.). Both present "stylistic opportunities" ${ }^{\prime 45}$ that can operate within more or less any given form. They are therefore "incorporated into Classic music rather than structured by it." Topics thus "mirror certain expressive stances, but they never assume the role of fundamentally structuring Classic music." ${ }^{\prime 46}$ This "expressive vocabulary" 47 relies on a "learned competence" of sensitivity to these conventions. From this competence, the analyst can construct a "plot" ("a coherent verbal narrative that is offered as an analogy or metaphor for the piece at hand"). This is not an explicit program but what Agawu calls a "sheer indulgence" arising from "the historically minded analyst's engagement with one aspect of a work's possible meaning." Referential topics are thus suggestive "points of departure" that "dynamically shape our response to Classic music." 48

Chapter three exposes the idea of introversive semiosis through Agawu's "beginningmiddle-end paradigm," a none-too-subtle conversion of Schenker's I-V-I Ursatz. These are "pure signs," structural tonics and dominants acting as signifiers of the dynamic function of a musical discourse that can operate on numerous hierarchical levels. They constitute the syntactic background to the referential foreground of the musical surfacethough referential topics can also exist in differing hierarchies. This point is attested by Agawu's earlier extroversive reading of the opening of Mozart's piano sonata K. 332 as a "background minuet" (mm. 1-12) "dramatized" by an "aria, musette" (mm. 1-4) and "learned style" (mm. 5-8) prior to the "default" emergence of a foreground minuet (mm. 12-22), newly "fused...in hunt style," breaking free from its former subservience. ${ }^{49}$ Indeed referential topics have a tendency, particularly in Mozart, to occur frequently in both "superimposition" and rapid "juxtaposition," terms that highlight a curious complementary relationship between the paratactic discourse of the rhetorical surface of Classical music and the hypotaxis of its underlying organic structure. See, for example, Agawu's observation on the opening of Mozart's piano concerto K. 467: "When the

44 Agawu's "universe of topics" comprises a "provisional" list of all the topics, twenty-seven in total, found in the works analyzed in his book. He acknowledges both the high degree of selectivity involved in this list and the inevitability that the universe will expand as "later research uncovers more topics" $(1991,30)$. As well as uncovering more topics, we might also add, with the benefit of the hindsight of Monelle's work, that many of the topics will undergo expansion by subdivision and by casting their referential net far wider than Ratner or Agawu envision. See for example Monelle's enlightening discussion of the web of references (semiotic, cultural, historic, contextual etc.) surrounding the horse and the pianto topics (2000, 41-80).

45 Pestelli 1984, 136.

46 Agawu 1991, 32.

47 Allanbrook 1983, 2-3.

48 Agawu 1991, 33-4.

49 Agawu 1991, 45. 
singing style emerges [m. 5] as a melody-biased topic, it does so as an additional layer superimposed on the march." ${ }^{50}$ The interaction between what is ultimately a syntactic background and a stylistic foreground enables Agawu ${ }^{51}$ to modify his "indulgent" notion of an extroversive "plot" into one dependent on the interaction between referential and pure signs. His concept of "structural rhythm" - borrowed from Kramer ${ }^{52}$ —is thus used to describe a musical discourse that emerges from the "dynamic transitions" between musical parameters as they progress through topics.

Semioticians know that meaning resides not in the signs themselves but in the relation among signs. For Agawu, the relation between referential and pure signs is frequently one of non-congruence. ${ }^{53}$ Indeed, as Monelle observes, "classical form is at its most expressive when the two levels [extroversive and introversive] are in disagreement; the basis of any expressive structure must be premised on the noncoincidence of domains." ${ }^{\prime 4}$ Agawu's case study in the noncongruence of introversive and extroversive discourse is the first movement of Beethoven's String Quartet in A minor Op. 132. ${ }^{55}$ Monelle ${ }^{56}$ eruditely summarizes the non-coincidence of structural landmarks with the fanfare, sensibility and cadenza topics that Agawu ${ }^{57}$ identifies in bars 19-22 (i.e. the fanfare is ill-placed on a Neapolitan chord; the appoggiaturas of the sensibility topic are displaced to just after the bass move from B flat to A; and the cadenza sets in just before the arrival on the second inversion). This microcosm of noncongruence is symptomatic of Agawu's findings for the whole movement, characterized by such dialectical events as the intrusion of a gavotte $(\mathrm{m} .40)$ in the progression to the second subject and the failure of a march to reach its expected harmonic goal, thwarted both by the introduction of a new theme and its frequent "lame" presentation with a missing harmonic downbeat. ${ }^{58}$ Op. 132 is one of three such extended examples of string quartets Agawu presents respectively in chapters four, five and six. Mozart's C Major Quartet K. 515 demonstrates the normative synchronization of topical surface with background structure, Haydn's D Minor Op. 76, No. 2 "represents a triumph of pure signs over referential signs," a constant struggle between referential signs and musical structure. Compelling though

50 Agawu 1991, 38.

51 Agawu 1991, 38-9.

52 Kramer 1984, 9-11.

53 Agawu is surely indebted here to Meyer's concept of "parametric non-congruence" (1973, 81); as Hatten also observes $(1992,91)$.

54 Monelle 1992, 229.

55 Agawu 1991, 110-26.

56 Monelle 1992, 229-30.

57 Agawu 1991, 114.

58 The impact on musical continuity of such noncongruence resonates with J. D. Kramer's concept of "gestural time," where time gestures are removed from their original context and become autonomous (for example, "beginning as ending." Kramer defines gestural time as "species of multiplydirected musical time in which the conventional meanings of gestures (beginnings, endings, structural upbeats, etc.), rather than the literal succession of events, determine the logic of continuity" (1988, 452).

59 Agawu 1991, 109. 
these analyses are in calibrating the dialectic between rhetorical surface and structural background, Hatten prepares the ground for his own substantial contribution to topic theory, raising the critique of Agawu's covert formalism:

The beginning-middle-end paradigm allows Agawu to coordinate deeper voice-leading and motivic structure with a dramatic musical surface-or rather to interpret the dialectic between the two...Ironically, despite the much richer analysis that such an interaction makes possible, the enterprise is disappointingly formalist; we simply have a more complex formal hierarchy with distressingly little expressive interpretation of either topical or syntactic functions. Agawu identifies drama, and the interactions which help produce it; but with his limited signifieds, he never reveals the interpretants that arise from, and help us appreciate, the expressive significance of the interaction. ${ }^{60}$

Hatten's first major contribution to topic theory Musical Meaning in Beethoven: Markedness, Correlation, and Interpretation (1994) addresses (indirectly) the formalist shortcomings of Agawu through his notion of "expressive genre" interpreted with a hermeneutic tool bag containing concepts of markedness theory, troping, and emergent meaning. These concepts enable Hatten to arrive at a far greater degree of expressive interpretation than Agawu approaches in his "play" of extroversive and introversive signs. The promise of Hatten's contribution to "second generation" topic theory is abundantly clear in his eloquent review of the polarized schools of "hermeneutic" (Agawu) and "structuralist" (Nattiez) semiotics/semiology. ${ }^{61}$ He articulates the "irony" of the distinction: ${ }^{62}$ Agawu's topics have far more potential for "abductive" interpretation in the vein of Peirce's semiotics (a system that "includes semantic [and pragmatic] interpretation") than his allegiance to Saussure might suggest; conversely Nattiez's "deductive" method of distributional analysis is far more akin to Saussure's semiology (a methodology that "requires as its complement a semantics to supply reference") than is suggested by Nattiez's allegiance to Peirce. The irony is crucial for Hatten. Both Nattiez and Agawu are criticized for offering "semiotic theories that underprivilege expressive interpretation;" Agawu neglects to fully interpret his topics, thus ignoring Peirce and producing "impoverished signifieds;" Nattiez in turn relegates interpretation to an activity that occurs only after the analysis of the neutral level, thus overlooking "the full implications of Peirce," namely "abduction, the role of the interpretant at every stage of the analysis, the final interpretant." ${ }^{\prime 63}$

Agawu's "underprivileging of expressive content" thus falls short for Hatten on two counts: he "does not fully define or categorize the topics he analyzes, nor does he go very far in interpreting the topical signs he decodes." ${ }^{14}$ These two critiques are particularly pertinent to both Hatten and Monelle who address these respective shortcomings. Monelle offers a much deeper cultural engagement with the definitions and categoriza-

60 Hatten 1992, 90.
61 Hatten 1992.
62 Hatten 1992, 88.
63 Hatten 1992, 97.
64 Hatten 1992, 89. 
tions of such topics as "the horse" and the "pianto"65 than anything found in Ratner, Allanbrook or Agawu; and the hermeneutic insights arising from Hatten's interpretation of "emergent meanings" in "troped" topics ${ }^{66}$ embrace a far more replete notion of musical signification than that found in Agawu.

Hatten views Agawu's attempt to transcend "an astylistic Schenkerism" as ultimately compromised by a focus on the "identification, not expressive interpretation," of topics. ${ }^{67}$ In semiotic terms, "the signifieds" of Agawu's topics are "hardly more than their labels, or a few of their identifying characteristics." ${ }^{168}$ A topic theory that confines itself to the identification of referential labels without attempting to extract their expressive meaning(s) is an impoverished theory; a point McClary deftly makes:

The mere labeling of topics in masterworks produces in me the kind of dismay I would feel if an art critic were to explicate Picasso's Guernica by proudly identifying the "horsie," without somehow noticing the creature's anguished grimace or the other figures on the canvas. ${ }^{69}$

Agawu's analysis of the first movement of Mozart's F major Sonata K. $332^{70}$ is to some extent guilty of this bland labelling, though he does attempt to articulate the relation among his found topics. ${ }^{71} \mathrm{He}$ charts, for example, the opposition between mm. 1-4 and mm. 5-8 as one between aria's "song" and learned style's "unsingable melody" (encoded in the form of a "parody of counterpoint," replete with hemiola effects and large melodic skips). Similarly, having identified the generally unstable topics of Sturm und Drang and fantasia in the aptly unstable location of transition ( $\mathrm{mm} .22-40)$, he goes on to note the suitability of the topic to its location. Such observations can form the basis of an "indulgent" interpretative plot or structural rhythm but Agawu (in this example, interested primarily in demonstrating the referential nature of extroversive signs) leaves this observation underdeveloped - a case of pointing to the horsie and the expression on its face but ultimately leaving semantic interpretation to the individual reader/listener. It is this pulling-up short of expressive meaning (particularly in instances where the suitability of the topic to its structural location is brought into question) that Hatten's topic theory addresses.

65 Monelle 2000, 41-80.

66 Hatten 1994; 2004.

67 Hatten 1992, 90.

68 Hatten 1992, 90.

69 McClary 2001, 326.

70 Agawu 1991, 44-8.

71 Agawu is explicit about this structuralist pursuit of finding meaning, not just in the identification of, but in the difference between and relation among signs/topics. "The identity of a topic is least dependent on the name of that topic. What matters, following the structuralist idea of relationality, is the difference between various topics...following Barthes...topics may be read or heard as at least second-order semiotic systems, since they take a musical sign (or set of musical signs), drain it of signification, and then refill it with meaning" $(1991,49)$. 
He argues that individual topics are organized into "expressive genres."72 By way of example, his opening "hermeneutic reading" of the slow movement of Beethoven's Hammerklavier Piano Sonata Op. 106 employs the expressive genre of the "tragic-totranscendent."73 This is signaled in the music by the "strategic" (i.e. work-specific) and "stylistic" (i. e. intertextual) undercutting of resolution, resulting in "transcendence through a positively resigned acceptance." Expressive meaning for the work is thus "troped" as "abnegation" - a positive surrender of the will to a higher power. ${ }^{74}$ Cook draws a helpful analogy here, noting that "expressive genres function rather like the key of a sonata." ${ }^{175} \mathrm{~A}$ work in A major, for example, is not continuously in A major "in any literal sense, but the overall key coordinates the diverse tonal contents of the music and so provides a means for interpreting them." ${ }^{176}$ In Hatten's words, "once a genre is recognized or provisionally invoked, it guides the listener in the interpretation of particular features...that can help flesh out a dramatic or expressive scenario." ${ }^{17}$ This process of guided interpretation based on the initial hypothesis of an expressive genre reveals Hatten's indebtedness to Peirce's notion of "abduction": ${ }^{78}$ a form of interpretative reasoning that proceeds from an initial supposition. ${ }^{79}$ For Hatten, then, "music embodies expressive processes...much as it embodies structural ones." ${ }^{180}$ Just as a key modulates, only to return to its tonic home, so too expressive genres control the overall expressive contour of a work, even if at times they are challenged by conflicting expressions.

Hatten achieves this extra level of expressive meaning through his device of "troping;" something akin to a purely musical metaphor. The opening of the finale of Op. 101, for example, conflates heroic and pastoral topics. Hatten reads this as a "heroic victory... within the realm of the pastoral." "If the pastoral is interpreted...in the context of the spiritual," he further surmises, "then the victory will be understood as an inward, spiritual one." ${ }^{\prime 1}$ This "emergent meaning" arises from the ("strong") troping of the heroic and pastoral topics. However, as Cook argues, ${ }^{82}$ such meanings constitute a form of "creative interpretation" that goes beyond the bounds of mere "historical reconstruction," the mast

72 Hatten 1994, 11.

73 Hatten 1994, 28.

74 Hatten 1994, 20.

75 Cook 1996, 108.

76 Cook 1996, 108.

77 Hatten 1994, 89; cited Cook 1996, 108.

78 Peirce 1958, 89-164.

79 Abductive reasoning is the interpretative process personified by William of Baskerville, the central character of Eco's The Name of the Rose (1998). It is an interpretative strategy (one proceeding from an initial, speculative hypothesis that governs all further reasoning) that is defined in contradistinction to the "deductive" processes of syllogistic logic. Deduction, of course, is the prototypical sleuthing tool employed by Sherlock Holmes, the character with whom Eco's novel invites comparison through the obvious intertextual parody of Baskerville's name.

80 Cook 1996, 108.

81 Hatten 1994, 171.

82 Cook 1996, 109. 
to which Hatten, like most topic theorists, nails his colors from the outset. ${ }^{83}$ Indeed much as the critical response to Agawu centers upon his balance between the extroversive style of hermeneutic interpretation and the introversive structure of analysis, so the critical reception to Hatten orbits two musicological poles: that of historically reconstructed meaning and the constructed meaning that arises from acts of creative interpretation. At times Hatten's flair for creative interpretation draws him uncomfortably close to a "new musicology" he is keen to distance himself from.

Hatten's interpretative theory further utilizes other parameters of music as signs that support or undercut his notion of expressive genres. These parameters include discriminations of dynamic levels, major/minor oppositions, types of key relationship (e.g. the prospective direction of dominant-sided modulations vs. the closural properties of subdominant sided modulations), and the direction of melodic motion. These are broadly articulated through binary oppositions that Hatten reads through a theory of "markedness," developed from Shapiro (1976; 1983). This theory of asymmetry between paired opposites holds that "marked" terms have a narrower range of meaning relative to "unmarked" ones. Thus, as Cumming (1994) summarizes, the major mode "is unmarked in relation to the more specific affective connotations of the minor" and "a 'middle' stylistic register is unmarked in relation both to 'high' and 'low' styles." Hatten also extends the concept to modulation-the home key is normative and modulation is marked. Even the basic semiotic opposition between type and token succumbs to markedness ratings: "the type is to be understood as unmarked and the token marked." ${ }^{84}$ Add to this a division of "material types" into "thematic/presentational, transitional/developmental, and cadential/closural"85_ a trio not entirely unrelated to Agawu's "beginning-middle-end" paradigm - and Hatten can creatively interpret the typicality of material type to its given location.

When presentational material occurs at an opening, or harmonically unstable material in a development section, it is unmarked because it conforms to the conventions of sonata form, but if any type of material is displaced to a location that is stylistically sensitized for another function, it is then marked by its incongruence. ${ }^{86}$

Hatten is thus able to distinguish between "stylistic markedness" when general style types appear in incongruous locations (a transitional fanfare, for example) and "strategic markedness" when such incongruence becomes foregrounded within an individual work's expressive genre. Through this, Hatten develops his sophisticated hermeneutic reading of Beethoven's music with his metaphor of "abnegation" (a positive surrender to a higher power) arising from the integration of opposed impulses (e.g. "yearning" melodic direction troped with "yielding" harmonic structure).

83 Hatten 1994, 1.

84 Hatten 1994, 44.

85 Hatten 1994, 115.

86 Cumming 1994. 
Hatten thus presents a topic theory with far more emphasis on creative interpretation by offering a framework for integrating ("troping") opposed topics as, in effect, meaningful metaphors. This takes place both on the extroversive level of semiosis (e.g. the heroic superimposed or juxtaposed with the pastoral) and on the introversive level where topics are troped in relation to structural landmarks and other "pure signs." Unlike Agawu, however, Hatten encompasses the clash of topics under overarching expressive genres that help to make sense of music's expressive discourse. (The [same] "Sense" of Music to which Monelle (2000) turns his attention.)

Although Hatten's theory is initially confined to Beethoven (later expanded to Schubert), ${ }^{87}$ the hermeneutic framework he builds in his topic theory offers a much wider utility beyond the classical repertoire. I, for one, have found this mode of readingcoupled with an adaptation of Bakhtin's (1981; 1984) literary theories of double-voicing in Dostoevsky's novels - to be highly productive on the early post-Rite of Spring works of Stravinsky. ${ }^{88}$ These works encode radical ("marked") oppositions in the music that call out for a similar mode of hermeneutic interpretation. And though the gestures that encode such oppositions in Stravinsky's syntax appear removed from the conventional commonplaces of Agawu's "universe of topics," their distance is often achieved through a willful negation of organic conventions that makes possible a reading of Stravinsky's rhetorical surface as referential through the "absent signifiers" of classicism. This enables one to construct a universe of antithetical topics in a parodic musical discourse; one that seeks to invert the conventional marked-unmarked identities that Hatten teases out of his readings of Beethoven.

The middle piece of Stravinsky's Three Pieces for String Quartet, for example, foregrounds what I have termed a "death of the theme" strategy. ${ }^{89}$ This is achieved diachronically, by usurping what should be prospective thematic locations with closural cadential gestures, and synchronically, by the absence of theme from accompanimental gestures. The work thus becomes one in which punctuation replaces statement. Whereas these intrusive punctuative gestures would be "marked" in the classical style rhetoric that Hatten studies, in Stravinsky's post-Rite world, they are so pervasive as to constitute the unmarked norm. In this sense Stravinsky's music can be said to have instigated what I call a "markedness reversal" (relative to classical repertoire). Semiotically, the work relies on antithetical gestures (e.g. cadential themes) frequently conveyed through absent signifiers (e.g. missing thematic statements). As this brief example demonstrates, Hatten's model of creative interpretation thus opens the door of topic theory to a far wider repertoire than the confines of his own Beethoven and Schubert studies might suggest. His hermeneutic approach, in other words, works just as well in such "marked," contexts as Stravinsky's "anti-classical discourses," as it does in its "unmarked" Beethovenian home.

The ever broadening remit of topic theory becomes yet more apparent in the two seminal works of Monelle (2000) and Hatten (2004), which I have loosely defined as marking a "second generation" of topic theory. Here Hatten offers a continuation and

87 Hatten 2004.

88 McKay 1998, 2003

89 McKay 2003, 500. 
development of the interpretative ideas set out in his earlier book (signaled by the reprise of these ideas at the outset). He begins with a powerful vindication of his continued attempt to situate interpretation in a topically-informed historical context against the relentless tide of Kramer's (1995) pervasive "new musicology." His defense is worth citing at length as a paradigm of the continuing territorial struggle to locate topic theory in contemporary musicology.

In seeking to establish a basis for musical meaning in a given composer's output (style types, their expressive correlations, and their further interpretation in musical workswithin the context of strategic events) one's role is analogous to that of a trial lawyer who must make a case, by creating plausible generalizations or narratives, that accounts for all the available evidence. Postmodernist approaches may consider this to be a flawed enterprise, impossible from the start, but I have found the results to reward to the effort. It is less a leap of faith for me to approach Beethoven's meanings in this way than it is for me to accept some of the associative leaps of a facile New Musicology, especially when they go beyond plausible intentions by historical individuals, to the unwitting psychological and cultural biases in which cultural subjects are inevitably trapped. I want to understand what Beethoven might have wanted to mean, not to psychoanalyze his efforts or to reduce him to a pawn of cultural forces beyond his control. Though my approach recognizes the stylistic and intertextual relationships that guarantee coherence of types and strategies from one work to the next, it also acknowledges the ways in which a composer can create works whose individuality lead to growth (or even change) of cultural values or meanings. Thus I would not dissolve the "autonomous" work into a mere node at the intersection of cultural practice, viewed through the peephole of present-day subjectivity, but rather reconceive the individual work as emerging from a dialectic of stylistic and strategic motivations as grounded in an historical context..$^{90}$

McClary is a notable target of Hatten's distancing of himself from the reader-oriented interpretation of postmodern musicology. Her infamous reading ${ }^{91}$ of Beethoven's Ninth Symphony (published the same year as Playing with Signs) through feminist codes of "sexual aggression" and the "violence" of the "patriarchically invested male" is an obvious example ${ }^{92}$ of the kind of "implausible" attempts to read Beethoven to which Hatten objects. Unlike his hermeneutic, such readings are rooted in frames of reference employing codes and conventions (e.g. constructs of gender, sexuality, and sociopolitical questions) that are decidedly not contemporary with the music studied. Part one of Hatten's book thus embellishes the idea of hermeneutics as historical reconstruction that he laid out in his earlier book. He develops his notion of troping to embrace what he terms a "trope at the level of genre;" evidenced in the Andante third movement of Beethoven's Op. 130 as a creative fusion of "the playfulness and rhythmic drive of a Scherzo with

90 Hatten 2004, 33-4.

91 McClary 2002, 112-31.

92 McClary's article was originally published in 1987 and substantially revized in 1991. Her reading provokes musicology into "getting down off the beanstalk;" a provocation prompting van den Toorn to riposte sharply in an impassioned defence of the so-called "Music Academy" (1995, 11-43). 
the tunefulness of an Andante." ${ }^{\prime 93}$ He employs Kramer's notion of "expressive doubling"94 as a marker of "self-reflexive shifts in the level of discourse" 95 and develops new expressive genres. Foremost among these is his "textural strategy" of "plenitude": "an implied saturation or repleteness," the "prototypical state" of which is "suffused, contented fulfillment." ${ }^{\prime 96}$ Hatten's exemplar is the Adagio of the Ninth Symphony. He further finds it in both "euphoric" (the Andante of Op. 130) and "dysphoric" (the Presto of Op. 130) states-terms reflecting the "state" of topics that Monelle also employs in his detailed interpretations of the horse topic. ${ }^{97}$ Hatten's discussion thus broadens that of his earlier oppositional theory of markedness in the direction of Rosch's (1976) so-called "prototypicality theory." ${ }^{\prime \prime 8}$

Much of the insightful recent work of both Hatten (2004) and Monelle (2000) is thus engaged with a much closer scrutiny of the typical effects and states of topics (as they would typically appear in their "unmarked" or "proto-type" state) in relation to their (often "marked" or deviant) concrete realizations as expressive tokens. This work represents a notable corrective to McClary's objection that (earlier) topic theorists simply point out the horsie without noticing the grimace on its face or its relation to its surrounds. Hatten and Monelle not only analyze the expressive gestures of music (with a detailed cultural and historic sensitivity more attuned to the diverse meanings of topics), they further draw illuminating meanings from their disposition among their surroundings. Through terminology indebted to Kramer's concept of the "structural trope," ${ }^{\prime 99}$ Hatten achieves this through his familiar notion of "emergent meaning," refining his concept through what he calls "the troping of topics;" a process that can occur both at the level of theme (the merging of two voices in contrasting topics) and genre (where all voices participate in the fusion).

He illustrates the distinction-helpfully for explicating the work of two books simultaneously - by borrowing Monelle's ${ }^{100}$ example of Bach's Fugue in Ab (WTC II). Its subject is a galant theme borrowed from the world of the trio sonata. Its countersubject is a passus duriusculus lament, typical of sixteenth-century expressions of the "pathetic, painful, distressed, tender, sorrowful, anxious." ${ }^{101}$ Hatten thus summarizes the "tropological signification of this combination of a cheerful, positive subject and a lament-based countersubject" as an example of thematic troping, perfectly illustrated by Monelle's reading of the incongruity as "a positive subject that 'dispels' the 'obscurity and neurasthenia of the countersubject'."102 The Gigue from Bach's first French Suite in D Minor, on

93 Hatten 2004, 37.

94 Kramer 1990, 22; cited Hatten 2004, 39.

95 Hatten 2004, 52.

96 Hatten 2004, 43.

97 Monelle 2000, 62-3.

98 For a discussion of Rosch's prototypicality theory, see Lakoff (1990, 39-114).

99 Kramer 1990, 10.

100 Monelle 2000, 198-206.

101 Monelle 2000, 198; cited Hatten 68.

102 Monelle 2000, 198; cited Hatten 68. 
the other hand, offers an example of troping at the level of genre: "a clear example of the use of French overture and fugue as topical treatments of a gigue":

The dotted rhythms and flourishes of the ceremonial French style, and the fugal treatment associated with the faster section of the French overture, so completely characterize the opening that one might ask in what sense the gigue is still present in the trope. But if one plays the dotted rhythms with the "swing" of a gigue, as opposed to the double-dotted French overture, and in a tempo that is faster than a ponderous overture but slower than a quick gigue, then the blend between the topics begins to emergeenergetic yet serious...Bach's trope is thus an ingenious way to enhance the expressive weight and closural force of the last dance, in keeping with the seriousness of the entire suite. $^{103}$

As well as exemplifying the type of expressive meanings both Hatten and Monelle read through their enhanced versions of topic theory, the last example points to another dimension in which Hatten has sought to develop the practice, one that curiously harks back to Ratner's suggestion that "for the performer... an awareness of referential implications can have a profound influence upon decisions for performance."104 The major development of Hatten's thought in his later book is thus a broadening of his remit of topics to take account of wider expressive "gestures;" a development that attempts to realize his longstanding belief that performance of the gestural contour of music can radically affect our interpretation of its expressive components.

Hatten traces the origins of this new approach to a moment of revelation when his initial (Brahms-influenced) interpretation of the second movement of Schubert's Piano Sonata in A Minor, D. 845 as simplistic and harmonically "formulaic," gave way under the influence of his piano tutor's performance. Through a formerly unimagined delicacy of touch and rubato this performance brought "the stylized Ländler...and Schubert's musical world to life" capturing "an implied inner agency's poignant evocation of lost innocence." ${ }^{\prime 105}$

My teacher's gesturally realized performance was composed of the very elements I had analytically treated as separate components. The difference was in their synthesis, their continuity beyond the mere sequence of enchained pitches and rhythms, which fostered an emergent expressive interpretation far richer than I had been able to achieve in my own playing. It is this synthetic gestalt, and its emergent expressivity, that will be central to my study of musical gesture. ${ }^{106}$

This offers a foretaste of Hatten's development of a hermeneutic of expressive gestures and agency, the full extent of which cannot be explicated in the confines of this article. ${ }^{107}$ In essence, expressive gesture is, for Hatten, the translation of cultural gestural com-

103 Hatten 2004, 68-9.

104 Ratner 1991, 616.

105 Hatten 2004, 111.

106 Hatten 2004, 112.

107 See Hatten's summary of his notion of gesture $(2004,124-6)$. 
petency to achieve a basic level of musical understanding (e.g. meter and tonality are analogous to "gravitation or dynamic vectoral space...making possible the experience of embodied motion...comparable to those affecting the body in a natural environment."108 Gestures are thus characterized ${ }^{109}$ as analogue, continuous, articulate, hierarchical, possessing a significant envelope (pre- and postmovement); contextually constrained and enriched (stylistically and strategically), typically foregrounded, beyond precise notation, amenable to type-token relationships, potentially systematic (i.e. organized oppositionally by type). Musical gesture is movement (implied, virtual, actualized) interpretable as a sign. It is classifiable according to Peirce's categories of firstness, secondness, and thirdness etc., etc. ${ }^{110}$

An example of what Hatten achieves with his synthesis of topic theory and gesture can be economically conveyed in his brief explanation of the finale of Beethoven's Op. 101. Here conflicting gestural agencies demand an interpretative shift from the dialectal integration of "the troping of topics" to a dialogical conflation of multiple agencies.

How might we interpret contrasting gestures when their tropological fusion does not appear to be warranted? Such gestures may imply more than one agency, and may be interpreted as dialogical...When musical events are heard as gestural, then the implication of agency is inescapable. In...Op. 101 we sense an agent who not only experiences an inner, spiritual victory, but also, in a performative sense... achieves it by affirmative utterance.... It is not enough that we hear the opening of the finale played "with determination;" we also need to hear the imitation that triggers the learned style; then, after the shift to a "softer" contrasting gesture in $\mathrm{m}$. 5, we must recognize the pedal point and continuous swirl of sixteenths that cue the pastoral through the musette topic. In other words we still need to be able to identify topics, as well as the details of harmony and voice-leading, rhythm, and meter that support their cueing in the context of a musical phrase. And we must recognize the stylistic expressive correlations which these topics bring to the creative synthesis of a musical trope. Not all of these elements of musical meaning are necessarily communicated through the Firstness or Secondness of gesture as performative realization, but they may depend on our knowledge of style conventions at the level of Thirdness. ${ }^{111}$

In other words, certain gestures "do not merge into a single agency but instead maintain their separate roles."112 They constitute what Hatten terms a "trope at the level of discourse: their opposite meanings interact dialogically, and rather than fusing metaphorically into a third meaning, they may create a trope at a higher level, as ironic wit emerges from their unassimilated friction." ${ }^{\prime 13}$ With this, Hatten broadens his theory to embrace a more pluralist conception of musical meaning than is possible with the singular dialectical synthesis obtained through metaphorically "troped topics." This opens his theory to

108 Hatten 2004, 124.

109 Hatten 2004, 124-26.

110 Hatten further summaries the distinction between stylistic and strategic gestures (136-7).

111 Hatten 2004, 224.

112 Hatten 2004, 225.

113 Hatten 2004, 225. 
more dialogical theories of interpretation that are less prone to "privilege" and "marginalize" certain voices or "agencies" at play in music. ${ }^{114}$ Hatten concludes his hermeneutic of topics and gesture with an acknowledgment that topics offer only a constituent element of expressive interpretation:

Although topics provide benchmarks for interpretation, much more is required to properly interpret those movements whose topics are far from prototypical. What we have observed in the finale of Op. 132 is a greater concern with continuity, and a perhaps compensatory move from the foregrounding of topics as subjects of discourse to the foregrounding of marked moments in themes that are less characterized by underlying topics. ${ }^{115}$

This is not to signal the death knell for topic theory as a mode of hermeneutic enquiry. Rather it is to signal that other forms of expressive "gestures" must be added to topical discourse and, with a nod to Monelle's exemplary work in this field, to signal that there remains much detailed semiotic work to be done in evaluating the varying prototypicality ratings of topical references.

In conclusion then, let us turn briefly to the work of Monelle's The Sense of Music (2000). Though it addresses topic theory explicitly only in chapters two and three, this text, perhaps more than any other, signals the future of topic research and interpretation. "Theory" no longer seems an apt word. As with Dr. Strabismus (the fictional music theorist, who at the onset of Monelle's book realizes the futility of his failed attempts to produce a "comprehensive theory of music"), The Sense of Music leaves us with a sense of the futility of attempting to produce a closed theory of topics that can synthesize what is an ever-expanding and near infinite "universe of topics" with anything remotely resembling systematic rules governing their paradigmatic meanings and syntagmatic deployments. His opening discussion of the subtle sign functions of (iconic or indexical) topics operating through ratio facilis (i.e. conventional learned codes), as opposed to the "uniqueness" of signs that operate through ratio difficilis (i.e. where every detail of the signified is mapped on to the signifier), highlights the evolutionary nature of signssomething that most topic theories fail to convey when they fix in print taxonomies of topics, each with their seemingly "fixed" associations:

Eco sees...that there is an irresistible interpretive landslip from ratio difficilis towards ratio facilis. Through habit, complex signs become "stylized"...though... a sign may contain many unique features, "we immediately recognize this large-scale configuration as if it were an elementary feature...the expression is recognized as being conventionally linked to a certain content" ...Through stylization, ratio difficilis may, by force of continuous exposure to communication and successive conventions, become a ratio facilis. Since music theorists are usually concerned with repertoire music ("classical" music), the defence of ratio difficilis may seem like a battle against the Philistines, against a

114 These themes of dialogical interpretation relate closely to Bakhtin's $(1981,1984)$ literary theory concepts of double voicing. For a discussion of the possible hermeneutic utility of these dialogical concepts in music, see Korsyn (1999) and McKay (2001; 2003).

115 Hatten 2004, 286. 
threat to lower all music to the level of a radio call sign or signature tune. Such a defence easily turns into fundamentalism, an anxious blindness to obvious aspects of musical expression. ${ }^{116}$

Once again we return to the metaphor of Asperger-like blindness to musical expression, symptomatic of formalism in the face of topic theorists' heightened sensitivities. Monelle's work, however, takes those sensitivities to a higher plane, moving from topics via historical investigation to cultural criticism. This is evident in his intricately detailed investigation of the horse topic. He opens up an intriguing world of military and equestrian history that discriminates between the "collected horse," valued for its ballet and dressage skills in seventeenth-century French cavalry riding schools, and the nineteenth-century battle-ready, savage, galloping horse. Thus nineteenth-century "musicians turned to the evocation of the ["noble"] galloping horse" both as a "sign of military success," recalled historically "through the medieval destrier" [a.k.a. "war-horse"] and "because modern wars were being won by cavalry charges."117 The sign, Monelle reveals, was motivated by a "literary topic that was medieval and legendary in origin."118

That "the noble horse is a male symbol" offers further intriguing insights into its use in "The Ride of the Valkyries" in Die Walküre (even though the riders and some of their mounts are female). ${ }^{119}$ We later learn there are in fact two discrete forms of the "Noble horse": the "euphoric, heroic destrier" and the "dysphoric, witches' ride;" the latter of which is built from the "association of the horse with death" that stems from the medieval image of "Death as warrior"120 and links witches with Valkyries as female harbingers of death. With this insightful cultural history in place, Monelle shames any hack topic theorist who has naively-labelled galloping music simply, "horse" and proceeds to link a chain of signifying associations between the witches' Sabbath of Berlioz's Symphonie fantastique, the Brocken in Goethe's Faust, and Wagner's Valkyries—some of whom, we now discover, ride mares because:

Just as the female gender was dysphoric, so the witch, being female, was not normally allowed to ride on a stallion, which was male, euphoric, positive, heroic; she was therefore condemned to ride a mare, a goat, or a broomstick. Nevertheless, her music, at least in nineteenth-century works, recalls the rhythm of the horse's hooves. ${ }^{121}$

All of this intriguing cultural history and intertextuality ripens the semiotic potency of topics and their hermeneutic implications. But, to end full circle by returning to Ratner, the primary function of such investigation is to highlight the shortcoming Monelle finds in Ratner's topic theory. "Ratner's mistake was to announce a basis in the writings of

116 Monelle 2000, 16.

117 Monelle 2000, 53-4.

118 Monelle 2000, 52.

119 "Ortlinde's horse is a Stute, a mare" (Monelle 2000, 52).

120 Monelle 2000, 62.

121 Monelle 2000, 62. 
contemporaries, that is, a historical basis for his ideas."122 As Spitzer argues, Monelle demonstrates that the contemporary (historical) sources Ratner cites to support his topics at best prove to be dubious. Monelle achieves this critique of Ratner "by out-historicizing the historians;" he "exposes Ratner's arguments as little more than a swindle, but only so as to place topics on a firmly theoretical, rather than historical, foundation." ${ }^{123}$ Indeed Monelle keenly observes that "some of the most important topics [including sensibility (Empfindsamkeit) and storm and stress (Sturm und Drang)] find no support at all."124 And as if that were not enough, Monelle goes on to observe: "finally, the theoretical idea itself - the notion that certain musical styles and figures were understood to signify particular cultural units, wherever they occurred-is almost specifically denied by the authors."125

Again this is not to strike the death knell for topic theory but to celebrate the new horizons for it that Monelle's work has undoubtedly opened. In the final analysis, Monelle charts the way forward-in light of his exemplary demonstration with the horse. The future of topic theory is one of cultural criticism grounded in a great deal of historical foraging:

Ratner should not be blamed for offering a fruitful idea without doing his homework properly. His musical instincts are true, and he must be thanked for bringing this idea to our notice. But contemporary writers are no good as buttresses of topic theory. Each topic needs a full cultural study. There is much work here for future doctoral programs. ${ }^{126}$

Perhaps this new generation of doctoral students will erradicate the last vestiges of Asperger syndrome-like insensitivity to music's expressive meanings, thereby releasing much formalist analysis from its past afflictions. This will surely be achieved only through a careful recalibration of hermeneutics and history. "Topic theory" will come of age only when it finds its footing more sensitively in its cultural contexts, from whence it can engender evermore perceptive reader-oriented acts of creative interpretation.

\section{Notes}

Agawu, V. Kofi 1991. Playing with Signs: A Semiotic Interpretation of Classical Music, Princeton, NJ, Princeton University Press.

1999. "The Challenge of Semiotics." In Rethinking Music. Edited by Nicholas Cook and Mark Everist. Oxford: Oxford University Press, 138-60.

122 Monelle 2000, 24.

123 Spitzer 2002, 507.

124 Monelle 2000, 24.

125 Monelle 2000, 28.

126 Monelle 2000, 33. 
Allanbrook, Wye J. 1996. "To Serve the Private Pleasure: Expression and Form in the String Quartets." In Wolfgang Amadè Mozart: Essays on His Life and His Music. Edited by Stanley Sadie. Oxford: Clarendon Press, 132-60.

—. 1983. "Rhythmic Gesture in Mozart: Le nozze di Figaro and Don Giovanni." Ph. D. diss., University of Chicago.

Bakhtin, Mikhail Mikhai Clovich. 1981. "Discourse in the Novel." In The Dialogic Imagination: Four Essays by M.M. Bakhtin, M. Holquist, Austin, TX: University of Texas Press, 259-422.

—. 1984. Problems of Dostoevsky's Poetics. Translated by C. Emerson. Minneapolis, MN: University of Minnesota Press.

Caplin, William E. 2005. "On the Relation of Musical Topoi to Formal Function." Eighteenth-Century Music 2/1: 113-24.

Coker, Wilson. 1972. Music and Meaning: A Theoretical Introduction to Musical Aesthetics. New York: The Free Press.

Cook, Nicholas. 1992. A Guide to Musical Analysis. London: J. M. Dent \& Sons Ltd.

—. 1996. "Putting the Meaning Back into Music, or Semiotics Revisited." Review of Musical Meaning in Beethoven: Markedness, Correlation, and Interpretation by Robert Hatten; A Theory of Musical Semiotics by Eero Tarasti. Music Theory Spectrum 18/1: 106-23.

Cumming, Naomi. 1994. "Measures of Meaning." Review of Musical Meaning in Beethoven: Markedness, Correlation and Interpretation by Robert S. Hatten. The Semiotic Review of Books 5/3: 2-4.

- 2000. Semiotics. Grove Music Online.

Dahlhaus, Carl. 1991. "Fragments of a Musical Hermeneutics." Current Musicology 50: 5-20.

Drabkin, William. 1991. Review of Playing with Signs: A Semiotic Interpretation of Classic Music by V. Kofi Agawu. Music Analysis 10/3: 381-7.

Dunsby, Jonathan and Arnold Whittall. 1988. Music Analysis in Theory and Practice. London: Faber.

Eco, Umberto. 1976. A Theory of Semiotics. Bloomington, IN: Indiana University Press.

—. 1998. The Name of the Rose. London: Vintage.

Forte, Allen. 1973. The Structure of Atonal Music. New Haven, CT, and London: Yale University Press.

Hanslick, Eduard. 1986. On the Musically Beautiful: A Contribution Towards the Revision of the Aesthetics of Music. Translated by G. Payzant. Indianapolis: Hackett Publishing Co.

Hatten, Robert S. 1992. Review of Playing with Signs: A Semiotic Interpretation of Classic Music by V. Kofi Agawu; Music and Discourse: Towards a Semiology of Music by Jean-Jacques Nattiez, Music Theory Spectrum 14/1: 88-98.

- 1994. Musical Meaning in Beethoven: Markedness, Correlation, and Interpretation. Bloomington, IN: Indiana University Press. 
—. 2004. Interpreting Musical Gestures, Topics, and Tropes: Mozart, Beethoven, Schubert. Bloomington, IN: Indiana University Press.

Hill, George R. 1981. "Classic Music: Expression, Form, and Style. By Leonard Ratner." Notes 38/1: 64-5.

Jakobson, Roman. 1971. "Language in Relation to Other Communication Systems." In Selected Writings. The Hague: Mouton.

—. 1985. "Closing Statement: Linguisitcs and Poetics." In Semiotics: An Introductory Anthology, editd by Robert E. Innis. Bloomington, IN: Indiana University Press, $147-75$.

Kerman, Joseph. 1980. "How We Got into Analysis, and How to Get Out." Critical Inquiry 7: 311-31.

- 1985. Musicology, London: Fontana.

Korsyn, Kevin. 1999. "Beyond Privileged Contexts: Intertextuality, Influence, and Dialogue." In Rethinking Music. Edited by Nicholas Cook and Mark Everist. Oxford: Oxford University Press, 55-72.

Kramer, Jonathan. 1988. The Time of Music: New Meanings, New Temporalities, New Listening Strategies. New York: Schirmer Books.

Kramer, Lawrence. 1984. Music and Poetry: The Nineteenth Century and After. Berkeley, CA: University of California Press.

—. 1990. Music as Cultural Practice, 1800-1900. Berkeley, CA: University of California Press.

—. 1995. Classical Music and Postmodern Knowledge. Berkeley, CA: University of California Press.

Lakoff, George. 1990. Women, Fire, and Dangerous Things: What Categories Reveal about the Mind. Chicago, IL: University of Chicago Press.

McClary, Susan. 2001. Review of Raymond Monelle, The Sense of Music: Semiotic Essays. Notes 58/2: 326-8.

—. 2002. Feminine Endings: Music, Gender, and Sexuality. Minneapolis, MN: University of Minnesota Press.

McKay, Nicholas. 1998. "A Semiotic Evaluation of Musical Meaning in the Works of Igor Stravinsky: Decoding Syntax with Markedness and Prototypicality Theory." Ph. D. diss., University of Durham.

—. 2002. Oedipus's Requiem: Verdi's "Voice" in Stravinsky. Verdi 2001: Atti del convengo internazionale Parma, New York, New Haven 24 gennaio - 1 febbraio 2001 (Historiae Musicae Cultores Bibliotheca). Edited by Fabrizio Della Seta, Roberta Montemorra Marvin and Marco Marica. Firenze, L. S. Olschki. II, 411-41.

—. 2003. "Igor's Eccentric Gestures: A Semiotic Decoding of Stravinsky's Syntax with Markedness Theory." In Musical Semiotics Revisited: Acta semiotica Fennica. Edited by Eero Tarasti. Helsinki: The International Semiotics Institute. XV, 498-510.

Meyer, Leonard B. 1973. Explaining Music. Berkeley, CA: University of California Press. 
Monelle, Raymond. 1992. Linguistics and Semiotics in Music. Chur, Switzerland: Harwood Academic Publishers.

—. 2000. The Sense of Music: Semiotic Essays. Princeton, NJ: Princeton University Press.

Nattiez, Jean-Jacques. 1975. Fondements d'une sémiologie de la Musique. Paris: Union Générale d'Editions.

—. 1982. "Varèse, 'Density 21.5': A Study in Semiological Analysis." Music Analysis 1/3: 243-340.

_. 1990. Music and Discourse: Toward a Semiology of Music. Princeton, NJ: Princeton University.

Newcombe, Anthony. 1984. "Once More Between Absolute and Programme Music: Schumann's Second Symphony." Nineteenth-Century Music 7/3: 233-50.

Noske, Frits. 1990. The Signifier and the Signified: Studies in the Operas of Mozart and Verdi. Oxford: Clarendon.

Peirce, Charles Sanders. 1958. Collected Papers. Cambridge: MA, Harvard University Press.

Pestelli, Giorgio. 1984. The Age of Mozart and Beethoven. Cambridge: Cambridge University Press.

Ratner, Leonard G. 1980. Classic Music: Expression, Form, and Style. New York: Schirmer books.

—. 1991. "Topical Content in Mozart's Keyboard Sonatas." Early Music 19/4: 615-19.

Rosch, Eleanor, Carolyn Mervis, et al. 1976. "Basic Objects in Natural Categories." Cognitive Psychology 8, 382-439.

Ruwet, N. 1987. "Methods of Analysis in Musicology." Music Analysis 6/1-2: 3-36.

Schenker, Heinrich. 1979. Free Composition. Translated by Ernst Oster. New York: Longman.

Shapiro, Michael. 1976. Asymmetry: An Inquiry Into the Linguistic Structures of Poetry. Amsterdam: North-Holland Publishing Co.

— 1983. The Sense of Grammar: Language as Semiotic. Bloomington, IN: Indiana University Press.

Spitzer, Michael. 2002. Review of The Sense of Music: Semiotic Essays by Raymond Monelle. Music \& Letters 83/3: 506-9.

Stravinsky, Igor. 1924. "Some Ideas About my Octuor." In The Arts, Brooklyn: 4-6.

—. 1990. An Autobiography (1903-1934). London: Marion Boyars Publishers Ltd.

- 1994. Poetics of Music in the Form of Six Lessons. Cambridge, MA: Harvard University Press.

Subotnik, Rose Rosengard. 1988. "Towards a Deconstruction of Structural Listening: A Critique of Schoenberg, Adorno, and Stravinsky." In: Explorations in Music, the Art, and Idea: Essays in Honor of Leonard B. Meyer. Edited by Eugene Narmour and Ruth A. Solie. Stuyvesant: Pendragon, 87-122. 
Tarasti, Eero. 1994. A Theory of Musical Semiotics. Bloomington and Indianapolis, IN: Indiana University Press.

Taruskin, Richard. 1987. "Stravinsky's 'Rejoicing Discovery' and What it Meant: In Defense of his Notorious Text Setting." In Stravinsky Retrospectives. Edited by Ethan Haimo and Paul Johnson. Lincoln, NE, and London: University of Nebraska Press, 162-99.

- 1995. "A Myth of the Twentieth Century: The Rite of Spring, the Tradition of the New, and the Myth itself." Modernism / Modernity 2/1: 1-26.

- 1996. Stravinsky and the Russian Traditions: a Biography of the Works through "Mavra". Oxford: Oxford University Press.

—. 1997. Defining Russia Musically: Historical and Hermeneutical Essays. Princeton, NJ, and Chichester: Princeton University Press.

—. 2003. "Stravinsky and Us." In The Cambridge Companion to Stravinsky. Edited by Jonathan Cross. Cambridge: Cambridge University Press, 260-84.

Van den Toorn, Pieter C. 1995. Music, Politics, and the Academy. Berkeley, CA: University of California Press.

Whitall, Arnold. 1996. Review of Musical Meaning in Beethoven: Markedness, Correlation, and Interpretation by Robert S. Hatten. Journal of the Royal Musical Association 121/1: 116-24. 